\title{
Keys to successful mentoring of undergraduate research teams with an emphasis in applied mathematics research
}

\author{
Hannah Callender Highlander \\ Department of Mathematics, University of Portland, Portland, OR, USA
}

\begin{abstract}
Independent of institution size and faculty research expectations, a growing number of colleges and universities encourage their undergraduates to engage in some form of research experience. To meet the demand of students seeking such experiences and to ensure these experiences are of high quality, it is imperative to have qualified mentors. While senior faculty rely on years of experience in mentoring research projects, professors stepping into these undergraduate mentoring roles at the graduate student or junior faculty level may not be as equipped to handle the potential hurdles unique to working with teams of undergraduates. This article is aimed at such an audience. Although much of the article is relevant to mentoring projects in any area of mathematics, some comments and suggestions are directed more to working with students in applied mathematics. This article includes advice gleaned from the National Science Foundation-sponsored Center for Undergraduate Research in Mathematics (CURM) faculty workshop in conjunction with personal experiences from the author, a CURM mini-grant recipient. The primary goals of the paper are to answer questions one might have when starting a project with undergraduates and to provide the reader with concrete steps to follow in planning and successfully completing such a project.
\end{abstract}

\section{ARTICLE HISTORY}

Received 21 November 2017

Accepted 22 November 2017

\section{KEYWORDS}

Undergraduate research; CURM; mentoring strategies; applied mathematics; junior faculty

\section{Introduction}

Undergraduate research is quickly becoming the expectation rather than the exception among college undergraduates, especially among those students planning to attend graduate school. More and more, graduate schools realize the benefit of research at early stages of education and therefore give priority or in some cases restrict admission entirely to students with research experience at the undergraduate level (Rampersaud, 2017; Webb, 2007). National funding agencies also recognize the importance of providing these opportunities for undergraduates. The Research Experiences for Undergraduates (REUs) model, which

CONTACT Hannah Callender Highlander 8 highland@up.edu

This is a reprint of an article originally published in the Proceedings of the 6th Annual Symposium on Biomathematics and Ecology Education and Research and has been accepted for publication in Letters in Biomathematics with explicit permission of the editors.

(c) 2017 The Author(s). Published by Informa UK Limited, trading as Taylor \& Francis Group.

This is an Open Access article distributed under the terms of the Creative Commons Attribution License (http://creativecommons.org/ licenses/by/4.0/), which permits unrestricted use, distribution, and reproduction in any medium, provided the original work is properly cited. 
receives funding from national funding agencies as well as universities, offers over 100 summer programs across the country in mathematics alone. Many of the websites for these REUs can be accessed through the American Mathematical Society's website (AMS website, 2017a). While REUs provide excellent opportunities for students to conduct research and gain experiences in working in research groups, this model often provides little training for the mentors, many of whom are either still in graduate school or have freshly crossed over into the role of assistant professor.

My first opportunity to help lead an REU team came in the summer of 2009 as I was completing my postdoctoral fellowship. While I had many opportunities in graduate school to interact with and collaborate with undergraduates, I was never an official research mentor. As a postdoc, even though I still was not the lead mentor, I gained several useful tools watching the primary mentor lead the students throughout our time together. Upon landing a tenure track position at a small liberal arts institution, I knew that I wanted to continue to provide valuable research experiences for my students, but I really had no idea where to start. My co-mentoring experience as a postdoc provided valuable insight, yet when it came time for me to step into the primary and sole mentor role, I harbored significant apprehension. My department and university were extremely supportive of my desire to create a research team, and I was blessed with several coworkers who were able to provide advice from their own experiences of working with students. However, out of all the resources at my disposal, no single entity provided better preparation than the Center for Undergraduate Research in Mathematics (CURM) mini-grant I received after my first year as an assistant professor. The information I came away with from the CURM faculty workshop changed the way I mentor and gave me the confidence I needed to successfully lead and sustain an undergraduate research programme in biomathematics at my institution.

This paper outlines the CURM model and includes a variety of mentoring strategies I learned from the CURM workshop. I include questions to consider when planning for undergraduate research in mathematics, with an emphasis in applied and interdisciplinary projects, and suggestions for tackling various aspects of undergraduate research mentoring.

\section{The CURM model}

Since its inception in 2006, CURM has funded mini-grants each year to faculty throughout the country. A National Science Foundation (NSF) grant received by Michael Dorff of Brigham Young University funds the mini-grants . As stated on the CURM website (Center for Undergraduate Research in Mathematics website, 2017), the primary goals of CURM are to:

- train professors as mentors for undergraduate students doing research;

- provide funds to professors to establish undergraduate student research groups;

- advise professors on how to organize and continue to operate undergraduate research groups; and,

- prepare undergraduate students to succeed in mathematics graduate studies and beyond.

The CURM model seeks to achieve these goals through a variety of methods, beginning with the faculty workshop that takes place during the summer before the research project 
begins. All grant recipients and CURM directors and co-directors meet for three days to discuss mentoring strategies. This workshop is where I gleaned the bulk of the information for this paper.

In addition to the initial training and ongoing networking provided by the CURM listserv, the mini-grant provides the bonus of a one semester course release for faculty members (many of whom have significant teaching loads) and pays the student researchers throughout the school year an equivalent to $10 \mathrm{~h}$ per week. Aside from the educational benefit of participating in research, this is a great incentive for students. It is designed to take the place of an on-campus job, therefore allowing the student to treat the research as a job and not just another academic requirement.

Mentors are asked to have at least two and up to four students working with them to encourage group collaboration. To support healthy collaboration, the CURM faculty workshop spends significant time discussing issues related to managing group dynamics in the undergraduate research setting.

As an underlying goal, the programme teaches students not only what it is like to think like a mathematician but also what is often required to be a mathematician in academia, where we often juggle course loads and research agendas simultaneously. This is one aspect of CURM that sets this experience apart from summer REUs, where students often have the research as their primary and, in many cases, only focus. By participating in a research project during the school year, students catch a glimpse into a year in the life of an academic mathematician, where they are challenged to find a balance between research and course work.

In line with this goal of training students to be well-rounded researchers in mathematics, CURM requires all students to give an oral presentation at the spring CURM conference and to submit a paper at the end of the school year which may lead to a publication. The faculty workshop covers topics related to supporting students through this process.

For more detailed information regarding CURM, including data showing the tremendous impact CURM is having on student success, the interested reader is encouraged to visit the CURM website (Center for Undergraduate Research in Mathematics website, 2017) and see the recent article by Kwembe, Leonard, and Pineda (2014).

The remainder of this article contains a summary of the information I collected at the faculty workshop as well as some of my experiences throughout the year with my CURM students.

\section{Getting started}

You have made the decision to work with undergraduates. So now what? Where do you begin? Here I will address some of the key questions you will need to consider as you plan your research project and select your team.

\subsection{Determine your desired outcomes}

It is important from the very beginning to be honest with yourself regarding your desired outcomes of the research experience. What do you want to get out of this? What do you want your students to get out of it? Do you merely want to have experience working with students, or do you expect to have new results by the end of your time together? Do you 
expect a publication? If so, for what journals are you aiming? Answering these types of questions in advance will improve your mentoring and will also increase the likelihood that this will be a positive experience for all involved. In particular, it helps you plan for the topics that follow.

\subsection{Pick an appropriate research problem}

In mathematics, it can be challenging to pick appropriate problems for undergraduates. During the 2010 CURM professors' workshop, the faculty participants created what we believed to be five general characteristics of good problems for undergraduate research; and I have added two additional characteristics that relate more specifically to applied and interdisciplinary projects. This list is primarily meant to serve as a proposed set of general guidelines to consider rather than strict rules to be applied across the board.

(1) Problems should require a limited amount of background for the students. This does not have to exclude topics in advanced areas of mathematics; however, it is important that the topic can be reduced to essential material which can be grasped quickly by the students you have selected.

(2) Problems should be specific and concrete rather than general and theoretical . Students should be able to determine what is being asked of them, even if they do not immediately understand the specifics of the problem.

(3) Problems should lead to exploration by computations, creating specific examples or using a computer. This way the student can begin with the more basic exercises of exploring examples to get an intuitive feel for the project before beginning to make conjectures or pose new hypotheses. The student can then work toward proving or testing, depending on the nature of the problem.

(4) Problems should be composed of several layers. In both stating the problem and in getting results, there should be a range from easy to very challenging. This way the students can first gain confidence by solving some of the lower hanging fruit and then proceed to more advanced layers. This can help to ensure that each student accomplishes something (certainly important if this happens to be one of your desired outcomes for your students), even if they do not end up proving the main result.

(5) The professor should have some ideas of how the problem might be solved and be able to guide students through hurdles along the way.

(6) The application of an applied problem should be readily understandable, apparent to the students and should be of interest to the students, professor and wider community; in other words, it should have potential to be published.

(7) Particularly for interdisciplinary teams, the problem should allow for individual contribution, but not without assistance from other group members. Group dynamics can be strengthened tremendously when each student can claim responsibility for his or her piece of the project but cannot complete that piece without the help, in some form, of fellow group members.

Aside from these general guidelines for characteristics of a good problem, there are some resources that can aid in finding introductory problems and general project ideas, such as the College Mathematics Journal (College Mathematics Journal Website, 2017), 
the American Mathematics Society Undergraduate page (AMS website, 2017b), and the MathForum website (MathForum Website, 2017). For detailed project ideas, the first volume of a new book series dedicated to open research problems for undergraduates in mathematics has recently been published (Wootton, Peterson, \& Lee, 2017).

\subsection{Select students}

When selecting students, an initial question might be where to find interested and qualified students. This is one of the many areas in which planning early is beneficial. Before answering this question, however, I suggest you consider these important questions that may connect back to your overall goals and expectations for the research experience: what type of students are you seeking? At what level would you prefer your students to be academically? Are you only interested in high-achieving students, or would you like to seek out students who have high potential but may not necessarily have the best academic record? What personality types will work well together and which ones will work well with you? If your research project is to be interdisciplinary, to what extent should your students reflect the nature of the project? In addition, how are you ensuring a diverse group of students? For instance, for my CURM project on Modeling the Dynamics of Cellular Motility, I had three students from various backgrounds. Two of the three were female; one was a first generation college student and hispanic; one was a sophomore engineering student, another was a junior mathematics major and the third was a senior biology major. Each of these students came into the project with varied academic and social backgrounds. This diversity of experience led to a rich team dynamic and allowed each student to contribute to the interdisciplinary project in a unique way.

Once you have answered these questions, you can begin to decide where you would like to find students who fit these criteria. If you have planned in advance, you can begin to keep an eye out in your own classes and talk to your colleagues about students they have encountered who would meet your qualifications. I found one of my research students among former students of mine, and the other two were recommended by colleagues. In the future, I plan to investigate a technique I have seen more in the experimental sciences, that of advertising for research students. I have noticed that when I ask a student personally if they want to do research with me, they may feel some obligation to say yes. If one of your goals is to have students who are truly interested in working with you, advertising might be a better option. The downside, of course, is the time involved in creating application forms and sifting through the submitted applications; however, the benefits of having students who have taken the time to apply and who are thus potentially more invested in the work could easily compensate for the time involved in selecting the students. Furthermore, many REU programmes use this process of advertising and reading applications; templates already exist and could be easily accessed online.

\section{Let the research begin}

Now that you have determined your primary goals and desired outcomes, devised a research plan, and selected your research team, it is now time to begin the actual research project. In this section I will outline specific practices I have found to be most beneficial to effective mentoring before, during, and after students are involved in the research project. 


\subsection{Set expectations early and often}

In the case of research during the academic year, one of the primary aspects to which I attribute most of my mentoring success is setting expectations early and often. I started emailing students from the moment I returned from the CURM workshop in June. I wanted to learn more about each student's background and provide any supplementary material necessary to get the students thinking about the project in advance so we could hit the ground running. I also wanted to set the tone early for how we would interact with one another. Therefore, in my initial emails, I sent introductory readings, some related to our project, and some, such as the 'Mathematician's survival guide' (Casazza, 2013) and 'Undergraduate Research: How Do We Begin?' (Bailey, Budden, Dorff, \& Ghosh-Dastidar, 2009), that focused more on preparing students for research in mathematics.

One of the CURM co-directors and former mini-grant recipients, Kathryn Leonard, wrote an article about her CURM experiences (Leonard, 2008). In this article, Leonard provided a list of questions she gave students relating to group dynamics. In one of my first emails to my students, which I sent a couple months before the beginning of the term, I included some of these questions, a few of my own and some of those posed by my fellow CURM professors during the workshop. The following is a subset of the questions I asked students to answer in their reply email:

(1) In past group experiences:

(a) What characteristics have worked for you?

(b) What characteristics haven't?

(2) How would you like to make group decisions?

(3) How would you like to share group work?

(4) What is the best way for you to hear/receive criticism?

(5) What happens if a student misses a meeting? What should be done?

(6) What is the best way for me to contact you?

(7) If you start to struggle, what is your plan?

(8) What are your expectations for this project? Of yourself? Of your group? Of me?

(9) Do you have any experience in using Matlab?

(10) What are your current questions or concerns?

During our first group meeting, we went over everyone's responses and held a valuable discussion on the different ways we handle conflict, constructive ways to give and receive criticism, and the different expectations we had of one another. I shared more of my expectations for students, such as attending all meetings, putting in the time required, having fun and constantly asking questions. It is amazing what you can learn from just a few questions like this. As one student opens up, it often provides relief for other students who are feeling the same way but are too afraid to admit it.

In response to question 7, one student wrote, 'I struggle with trying not to 'shut down' when I don't understand something, especially in math. When I reach a concept that I don't understand, I really benefit from having it explained several times. I struggle with this because I feel like I should remember more from my last math class, or I should be better at doing this, so on so forth.' The candor of the responses to these questions impressed me. During our first group meeting we discussed each student's response to all of the questions. This allowed us to immediately set expectations for the entire team. 
Student misconceptions and fears about working on a research project, working on a team and their own ability level were quickly addressed and dispelled as they realized they all felt similar levels of apprehension.

In response to question 10, another student, who had previously been involved in a summer REU, said, 'I'm a little concerned with the pace at which this will move. The only experience I have with research is the summer program, and that went so fast. I'm afraid that it will be the same way, and if it is, I'm afraid I won't be able to do research and school at the same time.' Again, during our first meeting we were able to discuss the ways in which research during the academic year would necessarily be different than during the summer. I was then able to calm their nerves by reassuring them I would be there each step of the way to provide guidance and motivation.

By asking these questions early on, I was able to ensure students were all starting from a similar place, that we knew the ways in which we each were similar and different in our preferred working styles, and that we were going to hold one another accountable and support one another throughout the process.

I cannot emphasize enough the importance of open and early communication with students and the importance of setting the tone as soon as possible. In this first meeting, I also shared more with the students about my long-term expectations. I began by addressing the amount of time I expected each of them to be working each week. During that meeting we scheduled group meeting times (those where I would be present and where they would be working without me) and reserved a room in the library for the students to meet twice a week.

To help keep students on track and to better inform my instruction during each group meeting, I also implemented student work logs. Students submitted work logs in LaTEX once a week. The logs were split into four sections: hours worked each day and with whom; understanding/progress made thus far; lingering questions; and additional comments (suggestions/concerns/complaints). These work logs not only helped students stay on task, but they also prompted the students to reflect on what they were learning and what questions they had along the way. In addition, they served as excellent tools for me to gauge student understanding and address issues in a timely fashion. Students posed great questions in these work logs. Often their questions would remind me of things I needed to cover in more detail, or they would pose new research questions I had not yet considered.

\subsection{Provide support and encouragement}

Throughout the research process, I have found it is important to remind students that I expect them to struggle. During the CURM workshop, the faculty mentors came up with the list below, which I discussed with students during our first group meeting and continued to remind students of throughout the year.

Twelve Things to Remember When Doing Math Research

(1) It's challenging but rewarding.

(2) Be patient, especially when learning background information.

(3) It is OKAY if you don't understand an idea the first time (or the second time, or the third time)

(4) We all get stuck and frustrated. 
- Take a break.

- Explain to someone (mathematically trained or not) why you are stuck.

- Review background material.

- See if the problem can be modified (problems are not set in stone).

- Check hypotheses or assumptions.

- Work out a simple example.

- Keep going.

(5) Don't be afraid to ask 'Why?'.

(6) Regularly share your ideas with others and attentively listen to those shared with you.

(7) Work as a team and trust your team members.

(8) Write down your work as you go.

(9) Be open to different ideas and approaches (and follow through).

(10) Research is time-consuming.

(11) Keep going. Persistence and focus are the keys to success.

(12) Celebrate each success, no matter how big or small.

As students hit roadblocks throughout the year, we would come back to this list to remind ourselves that while we expected these struggles to happen, we also have concrete tools with which to proceed through the frustration.

\section{Educate students in reading, writing and presenting mathematics research}

In addition to actually doing mathematics, it is important that students are able to read existing mathematics as well as write and present their own work. We all know the benefits of writing up one's work along the way; however, this takes much discipline, and many of us are often guilty of not following this advice in our own research. When it comes to research with undergraduates, with whom you have a limited time to get any results, writing along the way becomes crucial, especially if one of your goals is to submit a paper for publication.

The work logs were an excellent informal tool to motivate students to record their progress, but during our second semester together I also assigned regular written reports in LaTEX in the form of article drafts and oral presentations. Each student was in charge of a separate section of our final CURM report, and I asked for written drafts approximately once every other week. Starting these reports from the very beginning proved to be essential in assuring our final report was completed in time. This also gave me more insight into the struggles my students faced in fully understanding and communicating certain mathematical or biological concepts related to our project.

Regardless of the backgrounds of your students, you may wish to spend some time discussing how the reading and communication of mathematics is different from that of other disciplines. I found this to be especially beneficial for my non-math majors. Below I discuss a few tips I shared with students in each of these areas. 


\subsection{Reading mathematics}

Through teaching and mentoring undergraduate research, I have found that many students do not fully understand the differences in reading mathematics vs. reading other disciplines. Students with little experience or training in reading mathematics may be tempted to read too quickly and gloss over details that are difficult for them to immediately understand. Further, students may not realize this is actually not the best way to understand the mathematics they are reading. There are several excellent resources available to help students learn to read mathematics. One short yet powerful article can be found in Shai Simonson's book Rediscovering Mathematics (Simonson, 2011). Here Simonson provides four primary suggestions for students reading mathematics: don't miss the big picture; don't be a passive reader; don't read too fast; and make the idea your own.

\subsection{Writing skills}

Students' writing skills will naturally improve with practice, but there are a number of resources available on this topic. See, for example, Halmos's article 'How to Write Mathematics' (Halmos, 1970), which provides an in-depth perspective on quality writing in general, with some specifics related to mathematical writing. Another example used in both teaching and mentoring research in mathematics is Polya's classic How to Solve It (Polya, 1957). Though the book has been around for over half a century, much of Polya's advice remains relevant today. He provides not only excellent advice for students in the thinking and writing of mathematics but also valuable advice for instructors and mentors in helping students understand mathematics.

My students have also benefited from reading and then critiquing well-written and poorly-written articles. Too often my students read articles and, merely because it is in written word, believe it to be true and well-written. This exercise proved to be eye-opening for my students. I also had students read one another's writing. Before we discussed comments, I would remind them of helpful ways to give and receive criticism to make this experience as helpful as possible for each student. One interesting phenomena I noticed in this process is that students often put more time and effort into their work when it is reviewed by their peers. Peer review also reinforces the need for them to consider their audience as they are writing.

\subsection{Presentation skills}

During the CURM workshop we discussed ways to mentor students in giving presentations. Some of the general points we agreed students should remember while preparing a presentation include the following:

(1) Know your audience; the talk should be prepared for the people who will be listening to it.

(2) Be able to summarize what you did in one sentence and repeat this idea several times during the talk (e.g. beginning of talk, end of talk, etc.).

(3) Give simple examples to help the audience understand definitions, theorem, etc.

(4) Give motivation for why people should be interested in the result/theorem. 
(5) Have students practice several times with at least one of these times being in front of people not familiar with the research area.

Students should receive feedback on their presentations. I received a great deal of positive feedback from others in my department and at the CURM conference on how well my students presented their work. We went through many iterations of the talk before each of the two conferences and two colloquia where students presented. This practice was crucial.

Additional resources that my students found helpful include the video clips from Technically Speaking by Lew Ludwig, which (similar to showing students examples of high and low quality writing) present students with examples of good and bad, yet often entertaining, techniques of oral presentations (Ludwig, 2006). These video clips were based on Joseph Gallian's article 'Advice on Giving a Good PowerPoint Presentation' (Gallian, 2006). Additional pointers can be found in 'Helping Students Present Their Research' (Gallian \& Higgings, 2007).

\section{Anticipate conflict}

So far this article has provided suggestions to help you plan for mentoring students, including advice you can share with your students before and during the research process. However, there will inevitably be hurdles and conflict along the way, especially if you are working with a group of students. The key to successfully and quickly resolving conflict is to plan for it. One of the most beneficial exercises I participated in during the CURM workshop was brainstorming how we would handle certain issues if they were to arise. We went through each of the three scenarios mentioned below and came up with several ways we could address the problem.

Scenario 1: Student says he understands everything, but when he is asked to do something on his own, he returns the next time not having done anything and saying that he did not know how to proceed.

Scenario 2: Student is eager; starts dropping by the professors office more and more often to ask questions until it is becoming too overwhelming for the professor. The professor does not want to discourage the student.

Scenario 3: Student starts out well, but about half way through the CURM year, the student gets frustrated and starts to miss appointments and avoids contacting the professor.

The reader is encouraged to brainstorm potential conflicts which may arise and collectively explore solutions with the group. Some of these problems were a lot easier to answer when we realized the importance of setting expectations early and having early discussions with students on how we would all agree to handle conflict if and when it arose.

\section{Things to try next time}

While I feel the CURM workshop provided me with a strong foundation for mentoring a team of students, there are several areas I plan to improve upon in the future. For instance, I initially used the work logs to help keep my students on track and check to see that they were putting in the required time. After realizing the power, this tool held in understanding misconceptions and student concerns, I started using them more as guides for our research. In the future I plan to use these work logs even more and incorporate more of the article writing component into the work logs. 
A second area of improvement will be to practice presentations earlier and more often. Once we started practicing presentations in front of one another, I noticed that the students were less comfortable with speaking in front of people than they had initially realized or verbalized. I also want to try videotaping students. Each of the students had certain distracting habits that emerged when they started talking to a larger audience, and I think recording them could have helped them see how they come across to an audience.

Another area I would like to explore further is the idea of advertising for student researchers instead of hand-selecting all of them. There are pros and cons to each method, but I am interested to see if there is any noticeable difference in the type of students. One of my students who I believe agreed to the research simply because I asked proved to be the most challenging student with whom to work, both with myself and with the other team members. A large part of the struggle for this student was due to the fact that they were not as invested in the project. Since the student was accustomed to putting in little effort and still receiving top scores, they struggled when the research became more difficult. In the future, regardless of whether a student is hand-selected or submits an application, and regardless of whether or not the student receives A's in all of their classes, above all I hope to find students who are interested in working hard. Ultimately my experiences in mentoring students are in strong agreement with the wise observation from the famous karate master Tsutomu Ohshima: 'Those who achieve the most are not the most skilled, but are those who concentrate long after other have given up.'

\section{Conclusion}

Mentoring undergraduates in research is no easy task. It can be, however, one of the most rewarding endeavours. The more time you spend in advance to carefully lay out expectations and address potential conflict, the more likely this experience will prove to be a positive one for all involved. Though this was my first time as the primary and sole mentor of a team of undergraduates, all three of my students have gone onto do amazing things. The engineering student just landed a job in industry, the biology student will soon be leaving for a teaching position in Korea, and the mathematics student received a top fellowship for a $\mathrm{PhD}$ programme in computational biology. They all credit a significant portion of their success after graduation to the valuable lessons they learned during our time spent together. They are also now all published authors, as our manuscript, 'Mathematical Modeling of Integrin Dynamics in Initial Formation of Focal Adhesions' was published in Involve, A Journal of Mathematics (Blucher, Salas, Williams, \& Callender, 2014).

\section{Acknowledgements}

I would like to thank the CURM directors and co-directors as well as all of my fellow CURM grant recipients for all of their input that began during the CURM workshop and has continued since. This experience will forever shape the way I mentor.

\section{Disclosure statement}

No potential conflict of interest was reported by the author. 


\section{Funding}

CURM is funded by the National Science Foundation [grant number \#DMS-0636648], [grant number \#DMS-1148695], by Brigham Young University, and by sponsors.

\section{References}

AMS website. (2017a). Research experience for undergraduates summer programs. Retrieved November 9, 2017, from http://www.ams.org/programs/students/undergrad/emp-reu

AMS website. (2017b). American mathematical society website for undergraduate mathematics majors. Retrieved November 9, 2017, from http://www.ams.org/programs/students/undergrad/

Bailey, B., Budden, M., Dorff, M., \& Ghosh-Dastidar, U. (2009). Undergraduate research: How do we begin? MAA Focus, 29(1), 14-16.

Blucher, A., Salas, M., Williams, N., \& Callender, H. L. (2014). Mathematical modeling of integrin dynamics in initial formation of focal adhesions. Involve, a Journal of Mathematics, 7(4), 509-527. Retrieved from http://msp.org/involve/2014/7-4/involve-v7-n4-p05-s.pdf

Casazza, P. (2013). A mathematician's survival guide. Retrieved November 9, 2017 http://www. math.missouri.edu/ pete/pdf/140-MAA.pdf

College Mathematics Journal Website. (2017). Retrieved November 9, 2017, from http://www.maa. org/publications/periodicals/college-mathematics-journal/

Center for Undergraduate Research in Mathematics website. (2017). Retrieved November 9, 2017, from http://curm.byu.edu/

Gallian, J. A. (2006). Advice on giving a good powerpoint presentation. Math Horizons, 13(4), 25-27.

Gallian, J. A., \& Higgings, A. (2007). Helping students present their research. Proceedings of the Conference on Promoting Undergraduate Research in Mathematics, Arlington, VA, 273-278.

Halmos, P. R. (1970). How to write mathematics. L'Enseignement Mathématique, 16, 123-152.

Kwembe, T. A., Leonard, K., \& Pineda, A. R. (2014). Academic year undergraduate research: The CURM model. Involve, 7(3), 383-394. Retrieved from https://msp.org/involve/2014/7-3/ involve-v7-n3-p17-s.pdf

Leonard, K. (2008). Adventures in academic year undergraduate research. AMS Notices, 55(11), $1422-1426$.

Ludwig, L. (2006). Technically speaking. Retrieved November 9, 2017, from http://techspeaking. denison.edu/Technicallylchar'_Speaking/Home.html

MathForum Website. (2017). Retrieved November 9, 2017, from http://mathforum.org/

Polya, G. (1957). How to solve it (2nd ed.). Garden City, NY: Doubleday.

Rampersaud, R. (2017). Getting into graduate school: Advice from a grad student and an admissions officer. Journal of Young Investigators. Retrieved November 9, 2017, from http://www.jyi.org/ issue/getting-into-graduate-school/

Simonson, S. (2011). Rediscovering mathematics: You do the math. Mathematical Association of America.

Webb, S. A. (2007). The importance of undergraduate research. Science Careers. Retrieved November 9, 2017, from http://www.sciencemag.org/careers/2007/07/importance-undergraduate-research

Wootton, A., Peterson, V., \& Lee, C. (2017). A Primer for undergraduate research: From groups and tiles to frames and vaccines. Boston, MA: Birkhäuser Basel. 